\title{
Abnormal corticosteroid signalling in airway smooth muscle: Mechanisms and perspectives for the treatment of severe asthma
}

\author{
Latifa Chachi*, Adelina Gavrila*, Omar Tliba†, and Yassine Amrani*
}

*Department of Infection, Immunity and Inflammation, University of Leicester, University Road, Leicester, LE1 7RH, U.K †Department of Pharmaceutical Sciences, Thomas Jefferson University, Jefferson School of Pharmacy, Philadelphia, PA, USA.

Corresponding Authors: Dr Yassine Amrani, Institute for Lung Health, Department of Respiratory Medicine, Clinical Sciences Building, Glenfield Hospital, Groby Rd, Leicester, LE3 9QP, U.K. Phone: +44 116256 3794. Fax: +44 116 2502787. E-mail: ya26@le.ac.uk.

Acknowledgements: Performed in laboratories part-funded by ERDF \#05567 and supported by the National Institute for Health Research Leicester Respiratory Biomedical Research Unit. The views expressed are those of the author(s) and not necessarily those of the NHS, the NIHR.

Word count: 4016 


\begin{abstract}
Growing in vivo evidence supports the concept that airway smooth muscle produces various immunomodulatory factors that could contribute to asthma pathogenesis via the regulation of airway inflammation, airway narrowing and remodelling. Targeting ASM using bronchial thermoplasty has provided undeniable clinical benefits for patients with uncontrolled severe asthma who are refractory to glucocorticoid therapy. The present review will explain why the failure of glucocorticoids to adequately manage patients with severe asthma could derive from their inability to affect the immunomodulatory potential of ASM. We will support the view that ASM sensitivity to glucocorticoid therapy can be blunted in severe asthma and will describe some of the factors and mechanisms that could be responsible for glucocorticoid insensitivity.
\end{abstract}




\section{Introduction}

There is a body of in vitro evidence suggesting that targeting the "pro-inflammatory responses" in the airway smooth muscle (ASM), the main effector tissue regulating the bronchomotor tone, may lead to more effective therapies for asthma. ASM may play a role in the progression and/or perpetuation of asthma symptoms not only by regulating airway narrowing but more importantly via its extraordinary ability to secrete an array of inflammatory mediators which have the potential to regulate key asthmatic features including airway remodelling, airway inflammation and bronchial hyper-responsiveness (1-3). It is therefore not surprising to see that bronchial thermoplasty (BT), a recent bronchoscopy-based procedure that ablates ASM mass, is considered as a promising therapeutic option for the treatment of severe, uncontrolled asthma. Indeed, among the clear benefits of BT treatment include improvement in the quality of life and exacerbation rate (4-6). The clinical efficacy provided by BT points to two major conclusions. First, it does suggest that directly targeting ASM can offer a novel and effective way of treating patients with severe asthma. Second, it is possible that the failure of current pharmacological therapies to appropriately control severe asthma

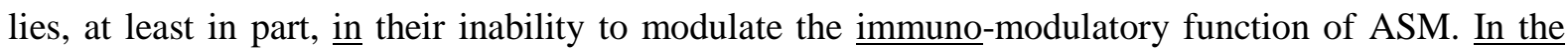
present review, we will summarize the key in vitro and in vivo reports showing that the antiinflammatory actions of glucocorticoids (GCs) in ASM may be blunted in patients with severe asthma, thus contributing to their reduced efficacy seen in these refractory patients.

\section{In vivo evidence showing the immunomodulatory potential of ASM in asthma}

The present section will not cover the numerous reports that have used cultured ASM cells to support the concept that ASM has the capacity to produce different "pro-asthmatic" mediators in asthma because this interesting area of research has been extensively discussed in excellent reviews (see $(3,7-9))$. Rather, we have decided to focus on the emerging in vivo evidence in patients with asthma demonstrating that ASM can produce a variety of immuno-modulatory factors that are capable of participating in the pathogenesis of the disease (summarized in Table 1). To address this question, several groups have relied on immunohistochemistry technique for staining structural tissues in endobronchial tissue sections. These groups have convincingly shown an increased expression of 
inflammatory mediators in ASM bundles of patients with asthma when compared to tissues from nonasthmatic subjects. Expression of chemokines such as CCL5 (10), CCL11 (11), CCL19 (12) and CX3CL1 (13) were reported to be elevated in asthmatic ASM tissues. The functional relevance of these chemokines was confirmed by in vitro studies using chemotaxis assays showing their chemoattractant activity towards different inflammatory cells including mast cells (CX3CL1) and eosinophils (CCL11 and CCL5). In addition to recruiting inflammatory cells, other mediators produced by ASM could act on these infiltrated immune cells and orchestrate the allergic responses within the lungs. Thus, ASM tissues from asthmatic subjects express high levels of thymic stromal lymphopoietin (TSLP) (14), a cytokine that has been shown to regulate Th2 response during in allergic diseases (15). TSLP has also been associated with the induction of GC insensitivity in an experimental model of allergic asthma (16). In ragweed-allergic asthmatic patients, segmental allergen challenge significantly increased protein expression of TNF-related apoptosis-inducing ligand (TRAIL) in the bronchoalveolar lavage (BAL) fluids as well as in various airway tissues including ASM. Neutralizing TRAIL function using blocking antibodies reveals its role in promoting eosinophil survival (17). IL-33 is another key cytokine potentially involved in the initiation and maintenance of local Th2 responses via its action on mast cells, T cells and eosinophils (18). Interestingly IL-33 was also demonstrated to be increased in the ASM tissues of patients with asthma (19). In addition, another study showed that IL-33 expression in the airways correlates with features of airway remodelling in paediatric patients with severe steroid-resistant asthma (20). The chemokine receptor CCR1 was found to be expressed in ASM tissues of asthmatics, although its role in asthma remains to be further investigated (21). CCL15, a ligand for CCR1, was recently reported to be highly expressed in asthmatic biopsies and produced by ASM cells (22). Similar to other chemokines, some have reported that CCL15 can promote the recruitment of monocytes and eosinophils in the airways in asthma (23).

In addition to attracting and activating infiltrated cells, these chemokines produced in vivo in ASM tissues may participate in asthma via altering the function of ASM itself. In vitro studies found that CCL19 and CCL11 act as potent chemo-attractants for ASM cells by activating the specific cell surface receptor CCR7 (12) and CCR3 (21), respectively. ASM migration can be induced by nerve 
growth factor (NGF) (24) which was also found to be significantly increased in ASM tissues of asthmatic patients (25). A recent report found that expression of pentraxin 3 (PTX3), an acute phase protein used as a serological biomarker for chronic inflammatory conditions, was significantly elevated in ASM bundles of severe asthmatics (26). The role of PTX3 in asthma has not yet been examined but the authors provided the first evidence that PTX3 can stimulate CCL11 production and inhibit mitogenic responses of ASM cells. Expression of Heparin-binding EGF (HB-EGF) was also elevated in ASM in asthma, correlated with disease severity and was upregulated in proliferating ASM (27). HB-EGF represents therefore a new marker of ASM hyperplasia in severe asthma. Finally, ADAM metallopeptidase domain 33 (ADAM33) was reported by two independent studies to be increased in ASM tissues in severe asthmatics $(28,29)$. Increased expression of ADAM33 was found to correlate with asthma severity (decreased $\mathrm{FEV}_{1}$ ), which could be explained by the ability of ADAM33 to directly alter ASM contractile properties (30).

Together, these reports provide undeniable evidence that ASM is capable of producing an array of immunomodulatory factors in vivo in patients with asthma. The role of these ASM-derived mediators in the pathogenesis of asthma could be concluded from various in vitro studies showing their dual chemotactic and activating potentials towards infiltrated key inflammatory cells (mast cells, T cells and eosinophils). These ASM-derived mediators were also shown to affect ASM function such as cell proliferation and mechanical properties (summarized in Figure 1).

\section{Impaired sensitivity of ASM to GCs in severe asthma}

It is yet unknown whether the clinical benefits provided by GC therapy in the vast majority of well-controlled patients with asthma could result, at least in part, from their direct action on ASM. Only one double-blind intervention study on steroid-free patients has examined whether a 14 days course with oral prednisolone $(0.5 \mathrm{mg} / \mathrm{kg} / \mathrm{day})$ was associated with changes in gene expression in ASM isolated by laser capture microdissection and analysed using the RNA-seq strategy. The authors made the interesting finding that oral prednisolone induced significant changes in ASM of 15 genes, 2 of which (called FAM129A and SYNPO2) were associated with bronchial hyper-responsiveness (31). The clinical importance of this study is twofold; first, it does reveal that oral GC therapy has a direct 
modulatory action on ASM in vivo which could contribute to their therapeutic actions in steroid responsive asthmatics. Second, the striking observation that different pro-asthmatic factors such as IL-33 (32), ADAM33 (28), CCL19 (12), TSLP (14) and pentraxin 3 (26) were still being expressed in ASM tissues of severe patients who were taking oral and/or high doses of inhaled GCs strongly suggests that the ability of GC therapy to suppress inflammatory gene expression in ASM is impaired in severe asthma. This possibility was initially suggested back in 2004 when Roth and colleagues discovered for the first time that a dysfunctional GC signalling (interaction with C/EBP $\alpha$ ) mediates the reduced anti-proliferative action of dexamethasone in ASM cells from asthma when compared to non-asthma subjects (33). Three elegant studies performed by Chung's group comparing severe and non-severe asthmatics have since provided additional proof for a reduced sensitivity of cultured ASM cells to GC in patients with severe asthma (34-36). The authors found that dexamethasone was less efficient (both in potency and maximum responses) in suppressing the production of CCL11 and CXCL8 induced by TNF $\alpha$ in severe asthmatic ASM cells. The mechanisms have not been fully characterized but the authors found an impaired nuclear translocation of GC receptor GR $\alpha$ in response to dexamethasone. Previous studies from the same group have demonstrated a role of a p38 MAPK in mediating GC sensitivity in alveolar macrophages from patients with severe asthma $(37,38)$. We have recently shown a critical role of p38MAPK in regulating GR $\alpha$ phosphorylation in healthy ASM cells (39). These studies show that GC insensitivity seen in both structural cells and immune cells could involve common mechanisms affecting GR $\alpha$ function through changes in receptor phosphorylation. Because GR $\alpha$ can be phosphorylated on multiple residues including serine 211, 203, and 226 (40), with different impacts on GR $\alpha$ function, it would be valuable to determine which phosphorylation sites (if any) are affected in severe asthma and the underlying mechanisms. We have unpublished evidence to suggest that abnormal GR $\alpha$ phosphorylation may explain the inability of dexamethasone to block the abnormal proliferative responses seen in ASM cells from severe asthmatics. The impaired in vitro GC sensitivity seen in ASM cells does not seem to be a specificity of patients with severe asthma. ASM cells derived from COPD patients, another condition characterized by poor sensitivity to GC therapy, have a reduced sensitivity to dexamethasone when compared to cells from non- 
smokers. Production of both CXCL8 and GM-CSF induced by TNF $\alpha$ was less sensitive to dexamethasone in ASM cells from COPD (41). Interestingly, GC insensitivity seen in ASM cells from both severe asthmatics $(34,35)$ or COPD patients (41) appears to be complex with the degree of GC impairment varying greatly according to the gene type studied. For example, while the inhibitory effect of dexamethasone towards CXCL8 and CCL11 was blunted in severe asthma, the enhancing effect of dexamethasone on cytokine-induced CX3CL1 production was not affected (34). Similarly, there was no difference in the inhibitory action of dexamethasone on the production of VEGF by TNF $\alpha$ in cells from COPD and non-COPD subjects (41). These studies raise the important conclusion that not all anti-inflammatory pathways activated by GC in ASM are dysfunctional in lung diseases characterized by GC refractoriness (severe asthma and COPD).

Collectively, these in vivo observations strongly support the current view that ASM may be a key player in severe asthma by being a source of different immuno-modulatory mediators. More importantly, the anti-inflammatory actions of GC therapy appear to be somewhat altered in ASM of severe asthmatics both in vivo in native tissues an in vitro in cultured cells. Future studies are required to fully understand the "pro-asthmatic" pathways that interfere with GC function in ASM in severe asthma. The following section will discuss some of the potential molecular mechanisms susceptible of blunting GC responsiveness in ASM cells.

\section{Pathways regulating GC sensitivity in ASM: lessons from our in vitro model}

The aforementioned evidence shows that the anti-inflammatory actions of GC are dramatically reduced in ASM in severe asthma as suggested by the in vivo expression of inflammatory mediators in ASM tissues and the persistence of this impaired GC sensitivity in vitro in cultured cells. In this section, we will summarize some of the potential mechanisms that impair GC function reported in our in vitro cellular model of GC insensitivity. Back in 2006, we made the surprising observation that the synergistic induction of the ectoenzyme CD38 in healthy ASM cells treated with TNF $\alpha / \mathrm{IFN} \gamma$ combination is resistant to the inhibitory action of fluticasone (42). The role of CD38 in asthma has been attributed to its ability to regulate the major allergic responses including bronchial hyperresponsiveness and airway inflammation (43). This initial observation led us to postulate that under 
inflammatory conditions, GC responsiveness could be altered in ASM cells. A number of subsequent studies have confirmed that the synergistic induction of "pro-asthmatic" mediators by both TNF $\alpha /$ IFN $\gamma$ in ASM cells was indeed insensitive to GC treatment (dexamethasone and fluticasone) (summarized in Table 2). GC-insensitive proteins include IL-33 (19), CXCL10 (44, 45), CX3CL1 (46), CCL5 (45, 47), CD38 (42) and CCL11 (45). Because the promoter region of the genes encoding for these proteins contains binding elements for the transcription factor NF- $\kappa \mathrm{B}$, it was thought that GC insensitive state induced by TNF $\alpha / \mathrm{IFN} \gamma$ was linked to the failure of GC to block NF- $\mathrm{BB}$ pathways. However, this seems be an unlikely possibility as the synergistic expression of another NFкB-inducible gene called CCL15 by TNF $\alpha / \mathrm{IFN} \gamma$ was found to be completely inhibited by dexamethasone (22). These data raise the prospect that GC insensitivity induced by TNF $\alpha /$ IFN $\gamma$ in ASM cells is highly complex and rather gene-specific as reported previously in ASM cells from severe asthmatics (see above section).

In subsequent studies we have uncovered some of the different mechanisms potentially explaining the loss of GC activity in ASM cells treated with TNF $\alpha /$ IFN $\gamma$. We demonstrated that the impaired cellular sensitivity to GCs induced by IFN $\gamma$ and TNF $\alpha$ was directly related to the modulation of GR $\alpha$ transactivation properties. Indeed, IFN $\gamma$ and TNF $\alpha$ simulated the expression of the dominant negative isoform GR $\beta$ (seen after 12 hour post stimulation) which is thought to interfere with GR $\alpha$ function through the formation of GR $\alpha / \operatorname{GR} \beta$ heterodimers (48). Although the role of GR $\beta$ in modulating GC signaling in lung diseases is still controversial (49), we found that fluticasone failed to induce GRE-dependent gene transcription and to suppress TNFo-induced CD38 expression in ASM cells transfected with constitutively active GRß (42).

We also demonstrated that GR $\beta$-independent mechanisms were involved in mediating cytokine-induced GC insensitivity. We found that at shorter incubation times ( $<6$ hour when GR $\beta$ was not induced) TNF $\alpha /$ IFN $\gamma$ treatment was still capable of blunting ligand-induced GR $\alpha$ transactivation activity when assessed using a GRE reporter vector (50). Silencing strategies combined with overexpressing approaches confirmed that the transcription factor interferon regulatory factor-1 (IRF1) was playing a key role in blunting fluticasone-induced GR $\alpha$ transactivation by competing for a 
common coactivator called glucocorticoid receptor interacting protein 1 (GRIP-1). GRIP-1 belongs to nuclear receptor coactivators p160 family (NCOA1/2/3) which act as transcriptional co-activators for a number of nuclear receptors. Three homologous members have been described, namely NCOA1/SCR1, NCOA2 (TIF2/GRIP-1/SRC2), and NCOA3 (RAC3/ACTR/pCIP/AIB-1/SRC3). These multifunctional coactivators interact with GC-bound GR $\alpha$ to recruit histone acetyltransferases and methyltransferases which facilitate the access of transcription factors to target gene promoters via the unpacking of the condensed chromatin network. These NCOA also interact and regulate the activity of a number of transcription factors including members of the IRF family (51). We made the novel observation that in ASM cells GRIP1 was critical for driving the transcriptional activities of both IRF-1 and GR $\alpha$ (52). We proposed the model whereby cytokine-induced accumulation of IRF-1 reduced ligand-induced GR $\alpha$ transcriptional activity by depleting GRIP-1 from GR $\alpha$ complex thus leading to GC insensitive state. There is some evidence to suggest a role of IRF-1 in asthma. Studies performed in patients found an association of polymorphisms in IRF-1 and a risk of atopy (53) and childhood atopic asthma (54). IRF-1 has the capacity to regulate the expression of a number of different inflammatory genes that are involved in asthma (55), and its levels are significantly increased in airway epithelium of asthmatic patients (56). The above studies show that IRF-1 has the potential to regulate airway inflammation and to diminish GC efficacy by blunting GR $\alpha$ transactivation activity. An elegant review has provided strong evidence for a role of transactivation in the anti-inflammatory actions of GC (57).

Phosphorylation of GR $\alpha$ can occur on three major residues located on its N terminus (ser203, ser211, and ser226) and regulates key functions including receptor turnover, subcellular trafficking, and activity. However, it is GR $\alpha$ phosphorylation on ser211 that is critical for its optimal transcriptional activity (58). We found that in addition to depleting GRIP-1 from GR $\alpha$, TNF $\alpha /$ IFN $\gamma$ treatment impaired GC transactivation in ASM cells by inhibiting fluticasone-induced GR $\alpha$ phosphorylation specifically at ser211, while no effect was seen at ser226. This dephosphorylating action could be prevented by silencing the protein phosphatase PP5 (59). A direct link between PP5 and inhibition of GR $\alpha$ function has been previously reported by Goleva and colleagues who showed 
that PP5 knockdown restored GC responsiveness in oestrogen-treated breast cancer cells (60). Our study was the first to suggest a similar role in ASM cells that was dependent on the potassium channel KCa3.1. Although little is known about the role of PP5 in asthma, there are growing reports to support a role of KCa3.1 channels in the pathogenesis of allergic asthma. In vitro studies showed that KCa3.1 channels regulate mast cell degranulation and migration (61-63), fibrocyte migration (64) and ASM proliferation (65). KCa3.1 channels also regulate migration of lung dendritic cells to different chemokines such as CCL19 and CCL21 (66). More convincing evidence comes from preclinical reports in animal models of asthma showing that specific KCa3.1 blockers can block the key allergic features of asthma including airway inflammation, remodeling and airway hyper-responsiveness (67, 68). We now show that KCa3.1 channels drive GC insensitivity in ASM cells (45), although it remains to be examined how cytokines actually activate KCa3.1 channels.

Almost nothing is known about the signalling pathways activated by KCa3.1 channels that regulate GC function. Most research so far has been focusing around the implication of KCa3.1 channels in the regulation of inflammatory gene expression in activated T cells, an effect that is likely due to changes in intracellular $\mathrm{Ca}^{2+}$ levels (69-71). Because our conclusions were based on the use of two selective blockers of the KCa3.1 pore, it is likely that KCa3.1 channel activity is responsible for driving GC insensitivity, possibly via its capacity to regulate levels of intracellular $\mathrm{Ca}^{2+}(72)$. This is a plausible mechanism as we found that cytokines such as TNF $\alpha$ can alter $\mathrm{Ca}^{2+}$ handling in ASM cells in part via the increased expression of $\mathrm{Ca}^{2+}$ regulatory proteins such as ectoenzyme CD38 (73) or transient receptor potential C3 channels (74). In addition we showed that expression of some inflammatory genes in ASM cells clearly involved $\mathrm{Ca}^{2+}$ pathways $(75,76)$. We therefore speculate that KCa3.1 channels promote GC insensitivity in ASM cells via the activation of $\mathrm{Ca}^{2+}$ dependent pathways (e.g., transcription factors) that decreased GR $\alpha$ function via changes in PP5 expression and/or activity. A report has indeed shown that PP5 function can be regulated by $\mathrm{Ca}^{2+}$ sensitive proteins called S100 which appear to regulate key cellular responses such as cell proliferation and gene expression (77). Additional studies are needed to determine the nature of the KCa3.1-dependent $\mathrm{Ca}^{2+}$ signalling pathways in ASM cells. 
Revised version CEA-2015-0100-UR-CJC

This in vitro model of cytokine-induced GC insensitivity allowed us to uncover multiple key proteins that act independently to one another but in concert to suppress GR $\alpha$ transactivation activity (see Figure 2). This state of GC insensitivity induced by TNF $\alpha /$ IFN $\gamma$ involved rapid inhibitory mechanisms (occurring within 6 hours) that include IRF-1-mediating dissociation of GR $\alpha$ from its essential co-activator GRIP-1 and PP5-dependent dephosphorylation of GR $\alpha$ at ser211 via functional KCa3.1 channels. This state of GC insensitivity induced by TNF $\alpha / \mathrm{IFN} \gamma$ also involved delayed inhibitory mechanisms (occurring after 12 hours) which impair GR $\alpha$ transactivation via the dominant negative action of GR $\beta$ isoform.

\section{Pathways requlating GC sensitivity in ASM: alternative mechanisms from recent studies}

Other potential mechanisms could also participate in reduced GC sensitivity to GCs seen in ASM cells from severe asthmatics especially with regard to the impaired GR $\alpha$ nuclear translocation (35). GCs exert their anti-inflammatory action in part via the recruitment of histone deacetylases (HDAC) to the inflammatory gene complex by the ligand activated GR $\alpha$ (48). A reduction in HDAC activity was found to correlate with the degree of GC insensitivity seen in PBMCs in severe asthma (78), an observation that could result from the failure of GCs to stimulate HDAC protein expression (79). Other studies found that GC insensitivity in PBMCs from refractory patients was associated with an impaired transactivation coupled with a reduced histone acetylation (80). Oxidative and nitrative stress via the inactivation of HDAC function has been described as a leading mechanism for driving corticosteroid insensitivity in both COPD and severe asthma $(48,81)$. One group recently demonstrated that cysteine oxidation can induce post-translational modification of GR $\alpha$ and impair its nuclear translocation (82). These are important observations as recent studies demonstrated that oxidative stress can affect a number of "pro-asthmatic" responses in ASM. An excessive mitochondrial production of reactive oxygen species contributes to the increased mitogenic response seen in the ASM cells of COPD patients (83). Our group also noted that NOX4-dependent oxidative $\underline{\text { stress was significantly increased in asthmatic ASM cells and was responsible for its hyper-contractile }}$ phenotype (84). It would be interesting to determine whether oxidative stress alters GC 
Revised version CEA-2015-0100-UR-CJC

responsiveness in ASM cells by modulating GR $\alpha$ signalling either via changes in HDAC activities or redox-related mechanisms.

There is also considerable evidence to suggest that serum levels of vitamin $\mathrm{D}$ can dramatically impact on the therapeutic responses of GCs in patients with asthma. Clinical studies both in children and adults with asthma have indeed demonstrated that low serum levels of vitamin $\mathrm{D}(<30$ ng/ml) were associated with either increased GC use (85) or reduced in vitro GC response (86), respectively. A more recent proof-of-concept clinical trial found that calcitriol therapy significantly improved clinical response to prednisolone in GC resistant asthmatics (87). The use of PBMCs from GC-resistant patients revealed that vitamin D could restore the ability of GC to stimulate expression of the anti-inflammatory cytokine IL-10 (88) or even enhanced GC-induced GR $\alpha$ activity as assessed by its recruitment to target gene promoter and levels of histone acetylation (89). Similarly, vitamin D restored the ability of GC to induce GR $\alpha$ nuclear translocation in the PBMCs of severe asthmatics (90). It would therefore be valuable to examine whether vitamin D supplementation could reinstate the abnormal GC sensitivity seen in ASM cells from severe asthmatics.

\section{Conclusive remarks}

Considering the clinical benefits of removing ASM using BT therapy in severe asthma and the demonstration that ASM produces in vivo different pro-asthmatic factors, it is now clear that ASM should be considered as a central player in the pathogenesis of asthma. In addition to impairing lung function via the modulation of airway narrowing, ASM can contribute to other key features of asthma via its extraordinary capacity of secreting an array of immuno-modulatory factors. These factors can participate in the chemo-attraction and activation of various inflammatory cells such as eosinophils, $\mathrm{T}$ lymphocytes and mast cells known to be infiltrated within the asthmatic airways. These ASM-derived factors can also contribute to other asthmatic features such as airway hyper-responsiveness and airway remodelling in part via an autocrine action on the proliferative and secretory functions of ASM.

There is also growing evidence to suggest that expression of pro-asthmatic factors by ASM specifically in severe asthmatics persists despite patients taking oral GC therapy. Our model of 
cytokine-induced GC insensitivity in healthy ASM cells has shed some light on the potential molecular players that are susceptible of altering GC function in ASM cells. These GC inhibitory signals that are capable of blunting GC transactivation properties include reduced access of the indispensable coactivator GRIP-1 for GR $\alpha$, dephosphorylation of GR $\alpha$ via KCa3.1-dependent PP5 activity and impaired GR $\alpha$ function via the dominant negative action of GR $\beta$. Our ongoing studies show that levels of PP5 are increased in vivo in ASM of severe asthmatics pointing toward an impaired phosphorylation of GR $\alpha$ (Chachi et al., manuscript in preparation). Recent elegant studies from Fan Chung's lab demonstrated that ASM cells isolated from severe asthmatics retain their GC insensitive state as seen in vivo in native tissues. This new model supports the current concept of abnormal GC sensitivity in severe asthmatic ASM and represents a unique opportunity to dissect potential factors that are interfering with GC signalling in severe asthma. 


\section{References}

1. Tliba O, Amrani Y. Airway smooth muscle cell as an inflammatory cell: lessons learned from interferon signaling pathways. Proceedings of the American Thoracic Society. 2008;5(1):106-12.

2. Knox A, Pang L, Johnson S, Hamad A. Airway smooth muscle function in asthma. Clinical and experimental allergy : journal of the British Society for Allergy and Clinical Immunology. 2000;30(5):606-14.

3. Zuyderduyn S, Sukkar MB, Fust A, Dhaliwal S, Burgess JK. Treating asthma means treating airway smooth muscle cells. The European respiratory journal : official journal of the European Society for Clinical Respiratory Physiology. 2008;32(2):265-74. Epub 2008/08/02.

4. Cox G, Thomson NC, Rubin AS, Niven RM, Corris PA, Siersted HC, et al. Asthma control during the year after bronchial thermoplasty. The New England journal of medicine. 2007;356(13):1327-37. Epub 2007/03/30.

5. Dombret MC, Alagha K, Philippe Boulet L, Yves Brillet P, Joos G, Laviolette M, et al. Bronchial thermoplasty: a new therapeutic option for the treatment of severe, uncontrolled asthma in adults. European respiratory review : an official journal of the European Respiratory Society. 2014;23(134):510-8. Epub 2014/12/03.

6. Wechsler ME, Laviolette M, Rubin AS, Fiterman J, Lapa e Silva JR, Shah PL, et al. Bronchial thermoplasty: Long-term safety and effectiveness in patients with severe persistent asthma. The Journal of allergy and clinical immunology. 2013;132(6):1295-302. Epub 2013/09/04.

7. Doeing DC, Solway J. Airway smooth muscle in the pathophysiology and treatment of asthma. J Appl Physiol (1985). 2013;114(7):834-43. Epub 2013/01/12.

8. Halayko AJ, Amrani Y. Mechanisms of inflammation-mediated airway smooth muscle plasticity and airways remodeling in asthma. Respir Physiol Neurobiol. 2003;137(2-3):209-22.

9. Xia YC, Redhu NS, Moir LM, Koziol-White C, Ammit AJ, Al-Alwan L, et al. Proinflammatory and immunomodulatory functions of airway smooth muscle: emerging concepts. Pulmonary pharmacology \& therapeutics. 2013;26(1):64-74. Epub 2012/05/29.

10. Berkman N, Krishnan VL, Gilbey T, Newton R, O'Connor B, Barnes PJ, et al. Expression of RANTES mRNA and protein in airways of patients with mild asthma. American journal of respiratory and critical care medicine. 1996;154(6 Pt 1):1804-11.

11. Ghaffar O, Hamid Q, Renzi PM, Allakhverdi Z, Molet S, Hogg JC, et al. Constitutive and cytokine-stimulated expression of eotaxin by human airway smooth muscle cells. American journal of respiratory and critical care medicine. 1999;159(6):1933-42. Epub 1999/06/03.

12. Kaur D, Saunders R, Berger P, Siddiqui S, Woodman L, Wardlaw A, et al. Airway smooth muscle and mast cell-derived CC chemokine ligand 19 mediate airway smooth muscle migration in asthma. American journal of respiratory and critical care medicine. 2006;174(11):1179-88.

13. El-Shazly A, Berger P, Girodet PO, Ousova O, Fayon M, Vernejoux JM, et al. Fraktalkine produced by airway smooth muscle cells contributes to mast cell recruitment in asthma. J Immunol. 2006;176(3):1860-8. Epub 2006/01/21.

14. Kaur D, Doe C, Woodman L, Wan WY, Sutcliffe A, Hollins F, et al. Mast cell-airway smooth muscle crosstalk: the role of thymic stromal lymphopoietin. Chest. 2012;142(1):76-85. Epub 2011/11/05.

15. Ziegler SF. The role of thymic stromal lymphopoietin (TSLP) in allergic disorders. Current opinion in immunology. 2010;22(6):795-9. Epub 2010/11/27.

16. Kabata H, Moro K, Fukunaga K, Suzuki Y, Miyata J, Masaki K, et al. Thymic stromal lymphopoietin induces corticosteroid resistance in natural helper cells during airway inflammation. Nature communications. 2013;4:2675. Epub 2013/10/26.

17. Robertson NM, Zangrilli JG, Steplewski A, Hastie A, Lindemeyer RG, Planeta MA, et al. Differential expression of TRAIL and TRAIL receptors in allergic asthmatics following segmental antigen challenge: evidence for a role of TRAIL in eosinophil survival. J Immunol. 2002;169(10):5986-96.

18. Borish L, Steinke JW. Interleukin-33 in asthma: how big of a role does it play? Current allergy and asthma reports. 2011;11(1):7-11. Epub 2010/10/12. 
19. Prefontaine D, Lajoie-Kadoch S, Foley S, Audusseau S, Olivenstein R, Halayko AJ, et al. Increased expression of IL-33 in severe asthma: evidence of expression by airway smooth muscle cells. J Immunol. 2009;183(8):5094-103. Epub 2009/10/06.

20. Saglani S, Lui S, Ullmann N, Campbell GA, Sherburn RT, Mathie SA, et al. IL-33 promotes airway remodeling in pediatric patients with severe steroid-resistant asthma. The Journal of allergy and clinical immunology. 2013;132(3):676-85 e13. Epub 2013/06/14.

21. Joubert P, Lajoie-Kadoch S, Welman M, Dragon S, Letuvee S, Tolloczko B, et al. Expression and regulation of CCR1 by airway smooth muscle cells in asthma. J Immunol. 2008;180(2):1268-75.

22. Joubert P, Lajoie-Kadoch S, Wellemans V, Letuve S, Tulic MK, Halayko AJ, et al. Expression and regulation of CCL15 by human airway smooth muscle cells. Clinical and experimental allergy : journal of the British Society for Allergy and Clinical Immunology. 2012;42(1):85-94. Epub 2011/11/19.

23. Shimizu Y, Dobashi K. CC-chemokine CCL15 expression and possible implications for the pathogenesis of IgE-related severe asthma. Mediators of inflammation. 2012;2012:475253. Epub 2012/12/22.

24. Freund-Michel V, Frossard N. Overexpression of functional TrkA receptors after internalisation in human airway smooth muscle cells. Biochimica et biophysica acta. 2008;1783(10):1964-71. Epub 2008/06/25.

25. Olgart Hoglund C, de Blay F, Oster JP, Duvernelle C, Kassel O, Pauli G, et al. Nerve growth factor levels and localisation in human asthmatic bronchi. The European respiratory journal : official journal of the European Society for Clinical Respiratory Physiology. 2002;20(5):1110-6.

26. Zhang J, Shan L, Koussih L, Redhu NS, Halayko AJ, Chakir J, et al. Pentraxin 3 (PTX3) expression in allergic asthmatic airways: role in airway smooth muscle migration and chemokine production. PloS one. 2012;7(4):e34965. Epub 2012/04/25.

27. Hassan M, Jo T, Risse PA, Tolloczko B, Lemiere C, Olivenstein R, et al. Airway smooth muscle remodeling is a dynamic process in severe long-standing asthma. The Journal of allergy and clinical immunology. 2010;125(5):1037-45 e3. Epub 2010/05/11.

28. Foley SC, Mogas AK, Olivenstein R, Fiset PO, Chakir J, Bourbeau J, et al. Increased expression of ADAM33 and ADAM8 with disease progression in asthma. The Journal of allergy and clinical immunology. 2007;119(4):863-71. Epub 2007/03/07.

29. Lee JY, Park SW, Chang HK, Kim HY, Rhim T, Lee JH, et al. A disintegrin and metalloproteinase 33 protein in patients with asthma: Relevance to airflow limitation. American journal of respiratory and critical care medicine. 2006;173(7):729-35. Epub 2006/01/03.

30. Lin F, Song A, Wu J, Jiang X, Long J, Chen J, et al. ADAM33 protein expression and the mechanics of airway smooth muscle cells are highly correlated in ovalbumin-sensitized rats. Molecular medicine reports. 2013;8(4):1209-15. Epub 2013/08/13.

31. Yick CY, Zwinderman AH, Kunst PW, Grunberg K, Mauad T, Fluiter K, et al. Glucocorticoid-induced changes in gene expression of airway smooth muscle in patients with asthma. American journal of respiratory and critical care medicine. 2013;187(10):1076-84. Epub 2013/03/16.

32. Prefontaine D, Nadigel J, Chouiali F, Audusseau S, Semlali A, Chakir J, et al. Increased IL33 expression by epithelial cells in bronchial asthma. The Journal of allergy and clinical immunology. 2010;125(3):752-4. Epub 2010/02/16.

33. Roth M, Johnson PR, Borger P, Bihl MP, Rudiger JJ, King GG, et al. Dysfunctional interaction of C/EBPalpha and the glucocorticoid receptor in asthmatic bronchial smooth-muscle cells. The New England journal of medicine. 2004;351(6):560-74. Epub 2004/08/06.

34. Chang PJ, Bhavsar PK, Michaeloudes C, Khorasani N, Chung KF. Corticosteroid insensitivity of chemokine expression in airway smooth muscle of patients with severe asthma. The Journal of allergy and clinical immunology. 2012;130(4):877-85 e5. Epub 2012/09/06.

35. Chang PJ, Michaeloudes C, Zhu J, Shaikh N, Baker J, Chung KF, et al. Impaired nuclear translocation of the glucocorticoid receptor in corticosteroid-insensitive airway smooth muscle in severe asthma. American journal of respiratory and critical care medicine. 2015;191(1):54-62. Epub 2014/11/21.

36. Perry MM, Baker JE, Gibeon DS, Adcock IM, Chung KF. Airway smooth muscle hyperproliferation is regulated by microRNA-221 in severe asthma. American journal of respiratory cell and molecular biology. 2014;50(1):7-17. Epub 2013/08/16. 
37. Bhavsar P, Hew M, Khorasani N, Torrego A, Barnes PJ, Adcock I, et al. Relative corticosteroid insensitivity of alveolar macrophages in severe asthma compared with non-severe asthma. Thorax. 2008;63(9):784-90. Epub 2008/05/22.

38. Bhavsar P, Khorasani N, Hew M, Johnson M, Chung KF. Effect of p38 MAPK inhibition on corticosteroid suppression of cytokine release in severe asthma. The European respiratory journal : official journal of the European Society for Clinical Respiratory Physiology. 2010;35(4):750-6. Epub 2009/10/21.

39. Bouazza B, Debba-Pavard M, Amrani Y, Isaacs L, O'Connell D, Ahamed S, et al. Basal p38 mitogen-activated protein kinase regulates unliganded glucocorticoid receptor function in airway smooth muscle cells. American journal of respiratory cell and molecular biology. 2014;50(2):301-15. Epub 2013/09/13.

40. Ismaili N, Garabedian MJ. Modulation of glucocorticoid receptor function via phosphorylation. Annals of the New York Academy of Sciences. 2004;1024:86-101. Epub 2004/07/22.

41. Knobloch J, Sibbing B, Jungck D, Lin Y, Urban K, Stoelben E, et al. Resveratrol impairs the release of steroid-resistant inflammatory cytokines from human airway smooth muscle cells in chronic obstructive pulmonary disease. The Journal of pharmacology and experimental therapeutics. 2010;335(3):788-98. Epub 2010/08/31.

42. Tliba O, Cidlowski JA, Amrani Y. CD38 expression is insensitive to steroid action in cells treated with tumor necrosis factor-alpha and interferon-gamma by a mechanism involving the upregulation of the glucocorticoid receptor beta isoform. Molecular pharmacology. 2006;69(2):588-96.

43. Jude JA, Dileepan M, Panettieri RA, Jr., Walseth TF, Kannan MS. Altered CD38/Cyclic ADP-Ribose Signaling Contributes to the Asthmatic Phenotype. Journal of allergy. 2012;2012:289468. Epub 2012/12/06.

44. Clarke DL, Clifford RL, Jindarat S, Proud D, Pang L, Belvisi M, et al. TNFalpha and IFNgamma synergistically enhance transcriptional activation of CXCL10 in human airway smooth muscle cells via STAT-1, NF-kappaB, and the transcriptional coactivator CREB-binding protein. The Journal of biological chemistry. 2010;285(38):29101-10. Epub 2010/09/14.

45. Chachi L, Shikotra A, Duffy SM, Tliba O, Brightling C, Bradding P, et al. Functional KCa3.1 channels regulate steroid insensitivity in bronchial smooth muscle cells. J Immunol. 2013;191(5):2624-36. Epub 2013/08/02.

46. Sukkar MB, Issa R, Xie S, Oltmanns U, Newton R, Chung KF. Fractalkine/CX3CL1 production by human airway smooth muscle cells: induction by IFN-gamma and TNF-alpha and regulation by TGF-beta and corticosteroids. American journal of physiology Lung cellular and molecular physiology. 2004;287(6):L1230-40. Epub 2004/08/24.

47. Banerjee A, Damera G, Bhandare R, Gu S, Lopez-Boado Y, Panettieri R, Jr., et al. Vitamin D and glucocorticoids differentially modulate chemokine expression in human airway smooth muscle cells. British journal of pharmacology. 2008;155(1):84-92. Epub 2008/06/17.

48. Barnes PJ. Corticosteroid resistance in patients with asthma and chronic obstructive pulmonary disease. The Journal of allergy and clinical immunology. 2013;131(3):636-45. Epub 2013/01/31.

49. Ammit AJ. Glucocorticoid insensitivity as a source of drug targets for respiratory disease. Current opinion in pharmacology. 2013;13(3):370-6. Epub 2013/02/26.

50. Tliba O, Damera G, Banerjee A, Gu S, Baidouri H, Keslacy S, et al. Cytokines induce an early steroid resistance in airway smooth muscle cells: novel role of interferon regulatory factor-1. American journal of respiratory cell and molecular biology. 2008;38(4):463-72.

51. Rollins DA, Coppo M, Rogatsky I. Nuclear Receptor Coregulators of the p160 family: Insights into Inflammation and Metabolism. Molecular endocrinology. 2015:me20151005. Epub 2015/02/04.

52. Bhandare R, Damera G, Banerjee A, Flammer JR, Keslacy S, Rogatsky I, et al. Glucocorticoid receptor interacting protein-1 restores glucocorticoid responsiveness in steroidresistant airway structural cells. American journal of respiratory cell and molecular biology. 2010;42(1):9-15. Epub 2009/10/07. 
53. Schedel M, Pinto LA, Schaub B, Rosenstiel P, Cherkasov D, Cameron L, et al. IRF-1 gene variations influence IgE regulation and atopy. American journal of respiratory and critical care medicine. 2008;177(6):613-21. Epub 2007/12/15.

54. Nakao F, Ihara K, Kusuhara K, Sasaki Y, Kinukawa N, Takabayashi A, et al. Association of IFN-gamma and IFN regulatory factor 1 polymorphisms with childhood atopic asthma. The Journal of allergy and clinical immunology. 2001;107(3):499-504. Epub 2001/03/10.

55. Savitsky D, Tamura T, Yanai H, Taniguchi T. Regulation of immunity and oncogenesis by the IRF transcription factor family. Cancer immunology, immunotherapy : CII. 2010;59(4):489-510. Epub 2010/01/06.

56. Sampath D, Castro M, Look D, Holtzman M. Constitutive activation of an epithelial signal transducer and activator of transcription (STAT) pathway in asthma. The Journal of clinical investigation. 1999;103(9):1353-6.

57. Newton R. Anti-inflammatory glucocorticoids: changing concepts. European journal of pharmacology. 2014;724:231-6. Epub 2013/06/12.

58. Galliher-Beckley AJ, Cidlowski JA. Emerging roles of glucocorticoid receptor phosphorylation in modulating glucocorticoid hormone action in health and disease. IUBMB life. 2009;61(10):979-86. Epub 2009/09/30.

59. Bouazza B, Krytska K, Debba-Pavard M, Amrani Y, Honkanen RE, Tran J, et al. Cytokines Alter Glucocorticoid Receptor Phosphorylation in Airway Cells: Role of Phosphatases. American journal of respiratory cell and molecular biology. 2012. Epub 2012/05/18.

60. Zhang Y, Leung DY, Nordeen SK, Goleva E. Estrogen inhibits glucocorticoid action via protein phosphatase 5 (PP5)-mediated glucocorticoid receptor dephosphorylation. The Journal of biological chemistry. 2009;284(36):24542-52. Epub 2009/07/10.

61. Cruse G, Duffy SM, Brightling CE, Bradding P. Functional KCa3.1 K+ channels are required for human lung mast cell migration. Thorax. 2006;61(10):880-5.

62. Duffy SM, Cruse G, Brightling CE, Bradding P. Adenosine closes the K+ channel KCa3.1 in human lung mast cells and inhibits their migration via the adenosine A2A receptor. European journal of immunology. 2007;37(6):1653-62.

63. Duffy SM, Cruse G, Lawley WJ, Bradding P. Beta2-adrenoceptor regulation of the K+ channel iKCa1 in human mast cells. The FASEB journal : official publication of the Federation of American Societies for Experimental Biology. 2005;19(8):1006-8.

64. Cruse G, Singh SR, Duffy SM, Doe C, Saunders R, Brightling CE, et al. Functional KCa3.1 $\mathrm{K}+$ channels are required for human fibrocyte migration. The Journal of allergy and clinical immunology. 2011;128(6):1303-9 e2. Epub 2011/08/30.

65. Shepherd MC, Duffy SM, Harris T, Cruse G, Schuliga M, Brightling CE, et al. KCa3.1 Ca2+ activated $\mathrm{K}+$ channels regulate human airway smooth muscle proliferation. American journal of respiratory cell and molecular biology. 2007;37(5):525-31.

66. Shao Z, Makinde TO, Agrawal DK. Calcium-activated potassium channel KCa3.1 in lung dendritic cell migration. American journal of respiratory cell and molecular biology. 2011;45(5):9628. Epub 2011/04/16.

67. Girodet PO, Ozier A, Carvalho G, Ilina O, Ousova O, Gadeau AP, et al. The KCa3.1 Blocker TRAM-34 Attenuates Airway Remodeling and Eosinophilia in a Mouse Asthma Model. American journal of respiratory cell and molecular biology. 2012. Epub 2012/12/04.

68. Yu ZH, Xu JR, Wang YX, Xu GN, Xu ZP, Yang K, et al. Targeted inhibition of KCa3.1 channel attenuates airway inflammation and remodeling in allergic asthma. American journal of respiratory cell and molecular biology. 2013;48(6):685-93. Epub 2013/03/16.

69. Beeton C, Barbaria J, Giraud P, Devaux J, Benoliel AM, Gola M, et al. Selective blocking of voltage-gated $\mathrm{K}+$ channels improves experimental autoimmune encephalomyelitis and inhibits $\mathrm{T}$ cell activation. J Immunol. 2001;166(2):936-44. Epub 2001/01/06.

70. Beeton C, Wulff H, Barbaria J, Clot-Faybesse O, Pennington M, Bernard D, et al. Selective blockade of $\mathrm{T}$ lymphocyte $\mathrm{K}(+)$ channels ameliorates experimental autoimmune encephalomyelitis, a model for multiple sclerosis. Proceedings of the National Academy of Sciences of the United States of America. 2001;98(24):13942-7. Epub 2001/11/22. 
71. Di L, Srivastava S, Zhdanova O, Ding Y, Li Z, Wulff H, et al. Inhibition of the K+ channel KCa3.1 ameliorates T cell-mediated colitis. Proceedings of the National Academy of Sciences of the United States of America. 2010;107(4):1541-6. Epub 2010/01/19.

72. $\quad$ Bradding $\mathrm{P}$, Wulff $\mathrm{H}$. The $\mathrm{K}+$ channels $\mathrm{K}(\mathrm{Ca}) 3.1$ and $\mathrm{K}(\mathrm{v}) 1.3$ as novel targets for asthma therapy. British journal of pharmacology. 2009;157(8):1330-9. Epub 2009/08/18.

73. Deshpande DA, Walseth TF, Panettieri RA, Kannan MS. CD38-cyclic ADP-ribose-mediated $\mathrm{Ca} 2+$ signaling contributes to airway smooth muscle hyperresponsiveness. The FASEB journal : official publication of the Federation of American Societies for Experimental Biology. 2003:FASEB Journal Express Article 10.1096/fj.02-0450fje.

74. White TA, Xue A, Chini EN, Thompson M, Sieck GC, Wylam ME. Role of transient receptor potential C3 in TNF-alpha-enhanced calcium influx in human airway myocytes. American journal of respiratory cell and molecular biology. 2006;35(2):243-51. Epub 2006/04/01.

75. Amrani Y, Lazaar AL, Hoffman R, Amin K, Ousmer S, Panettieri RA, Jr. Activation of p55 Tumor Necrosis Factor-alpha Receptor-1 Coupled to Tumor Necrosis Factor Receptor-Associated Factor 2 Stimulates Intercellular Adhesion Molecule-1 Expression by Modulating a ThapsigarginSensitive Pathway in Human Tracheal Smooth Muscle Cells. Molecular pharmacology. 2000;58(1):237-45.

76. Tliba O, Panettieri RA, Jr., Tliba S, Walseth TF, Amrani Y. Tumor necrosis factor-alpha differentially regulates the expression of proinflammatory genes in human airway smooth muscle cells by activation of interferon-beta-dependent CD38 pathway. Molecular pharmacology. 2004;66(2):322-9.

77. Yamaguchi F, Umeda Y, Shimamoto S, Tsuchiya M, Tokumitsu H, Tokuda M, et al. S100 proteins modulate protein phosphatase 5 function: a link between CA2+ signal transduction and protein dephosphorylation. The Journal of biological chemistry. 2012;287(17):13787-98. Epub 2012/03/09.

78. Hew M, Bhavsar P, Torrego A, Meah S, Khorasani N, Barnes PJ, et al. Relative corticosteroid insensitivity of peripheral blood mononuclear cells in severe asthma. American journal of respiratory and critical care medicine. 2006;174(2):134-41. Epub 2006/04/15.

79. Cosio BG, Mann B, Ito K, Jazrawi E, Barnes PJ, Chung KF, et al. Histone acetylase and deacetylase activity in alveolar macrophages and blood mononocytes in asthma. American journal of respiratory and critical care medicine. 2004;170(2):141-7. Epub 2004/04/17.

80. Matthews JG, Ito K, Barnes PJ, Adcock IM. Defective glucocorticoid receptor nuclear translocation and altered histone acetylation patterns in glucocorticoid-resistant patients. The Journal of allergy and clinical immunology. 2004;113(6):1100-8. Epub 2004/06/23.

81. Marwick JA, Ito K, Adcock IM, Kirkham PA. Oxidative stress and steroid resistance in asthma and COPD: pharmacological manipulation of HDAC-2 as a therapeutic strategy. Expert opinion on therapeutic targets. 2007;11(6):745-55. Epub 2007/05/17.

82. Stephenson ST, Brown LA, Helms MN, Qu H, Brown SD, Brown MR, et al. Cysteine oxidation impairs systemic glucocorticoid responsiveness in children with difficult-to-treat asthma. The Journal of allergy and clinical immunology. 2015. Epub 2015/03/10.

83. Wiegman CH, Michaeloudes C, Haji G, Narang P, Clarke CJ, Russell KE, et al. Oxidative stress-induced mitochondrial dysfunction drives inflammation and airway smooth muscle remodeling in patients with chronic obstructive pulmonary disease. The Journal of allergy and clinical immunology. 2015. Epub 2015/04/02.

84. Sutcliffe A, Hollins F, Gomez E, Saunders R, Doe C, Cooke M, et al. Increased nicotinamide adenine dinucleotide phosphate oxidase 4 expression mediates intrinsic airway smooth muscle hypercontractility in asthma. American journal of respiratory and critical care medicine. 2012;185(3):267-74. Epub 2011/11/24.

85. Searing DA, Zhang Y, Murphy JR, Hauk PJ, Goleva E, Leung DYM. Decreased serum vitamin D levels in children with asthma are associated with increased corticosteroid use. J Allergy Clin Immun. 2010;125(5):995-1000.

86. Sutherland ER, Goleva E, Jackson LP, Stevens AD, Leung DYM. Vitamin D Levels, Lung Function, and Steroid Response in Adult Asthma. American journal of respiratory and critical care medicine. 2010;181(7):699-704. 
87. Nanzer AM, Chambers ES, Ryanna K, Freeman AT, Colligan G, Richards DF, et al. The effects of calcitriol treatment in glucocorticoid-resistant asthma. The Journal of allergy and clinical immunology. 2014;133(6):1755-7 e4. Epub 2014/05/03.

88. Gupta A, Sjoukes A, Richards D, Banya W, Hawrylowicz C, Bush A, et al. Relationship between serum vitamin $\mathrm{D}$, disease severity, and airway remodeling in children with asthma. American journal of respiratory and critical care medicine. 2011;184(12):1342-9. Epub 2011/09/13.

89. Zhang Y, Leung DYM, Goleva E. Vitamin D Enhances Glucocorticoid Action in Human Monocytes INVOLVEMENT OF GRANULOCYTE-MACROPHAGE COLONY-STIMULATING FACTOR AND MEDIATOR COMPLEX SUBUNIT 14. Journal of Biological Chemistry. 2013;288(20):14544-53.

90. Lan N, Luo G, Yang X, Cheng Y, Zhang Y, Wang X, et al. 25-hydroxyvitamin D3-deficiency enhances oxidative stress and corticosteroid resistance in severe asthma exacerbation. PloS one. 2014;9(11):e111599. Epub 2014/11/08. 


\section{Figure legends}

Figure 1: Role of the immuno-modulatory factors produced in vivo by ASM in asthma pathogenesis. The different mediators expressed in vivo in ASM tissues of severe asthma have the capacity to contribute to regulate key asthmatic features. These immunomodulatory factors could act on ASM in an autocrine manner to regulate various pro-remodelling ASM responses including migration, proliferation and abnormal contractility (e.g., ADAM33). Other factors include various chemokines which act as chemoattractants for eosinophils, $\mathrm{T}$ lymphocytes and mast cells within the airways. Finally, other ASM-derived factors such as IL-33, TSLP and TRAIL could participate in the local airway inflammation by acting on infiltrated inflammatory cells and orchestrating the TH2 allergic responses and survival of eosinophils. In addition to its role in airway inflammation, TSLP has been recently described to participate in GC insensitivity via its action of natural helper (NH) cells, a member of group 2 innate lymphoid cells (ILC2s). IL-33 has been associated with the development of airway inflammation and airway hyper-responsiveness possibly via an action on the epithelium and mast cells.

Figure 2: Potential molecular mechanisms mediating cytokine-induced GC insensitivity in ASM cells. TNF $\alpha /$ IFN $\gamma$ drive GC insensitivity in ASM via different inducible proteins that are capable of blunting GR $\alpha$ function through 2 main mechanisms (defined as rapid and delayed). These mechanisms, independent from one another, act in concert to specifically suppress GC-induced GR $\alpha$ transactivation activity. This rapid inhibitory mechanisms (that occur within 6 hours) mediating GC insensitivity induced by TNF $\alpha /$ IFN $\gamma$ comprises i) the induction of the transcription factor IRF-1 which deplete GR $\alpha$ from its indispensable transcriptional co-activator GRIP-1 and ii) the KCa3.1 channel-dependent upregulation and activation of the phosphatase PP5 which dephosphorylates GR $\alpha$ specifically at serine 211 site that is essential for its transcriptional activity. The delayed inhibitory mechanisms (occurring 12 hours post-cytokine stimulation) mediating GC insensitivity induced by $\mathrm{TNF} \alpha / \mathrm{IFN} \gamma$ involves the upregulation and action of the dominant negative GR $\beta$ isoform. Both rapid and delayed mechanisms contribute to the overall GC insensitivity induced by TNF $\alpha /$ IFN $\gamma$ in healthy ASM cells. It remains to be determined how $\mathrm{TNF} \alpha / \mathrm{IFN} \gamma$ regulates the expression of these different proteins which interfere with GC signaling and if they are expressed both in vivo and in vitro in ASM in severe asthma. 